Nuilane Raquel Lago dos Santos

E-mail: nuilanelago@outlook.com

Orientação do trabalho: Prof ${ }^{\circ}$ Me. Jurandir Eduardo

\title{
A mulher que digita e dita por meio do figurino: um estudo sobre gênero e traje de cena
}

\begin{abstract}
RESUMO
O pôster busca evidenciar o meu processo criativo na criação do traje de cena do personagem "a mulher que digita e dita"; do texto "A mulher que digita” de Carla Kinzo. A presente reflexão textual e visual pretende apresentar as articulação direta com questão de gênero e a criação de um traje de cena, destacando e refletindo através das dificuldades que enfrentei para elaboração do referido traje de cena. A investigação é oriunda do LABTC- Laboratório de Pesquisa sobre Traje de Cena que tem como um dos objetivos oportunizar discussões que interseccionam figurino e gênero. A proposta do laboratório de forma metodológica está na articulação entre teoria e pratica não de forma dicotômicas, mas conjugadas no exercício do figurinista pesquisador (a). Para está inclusão criativas tive como recorte teórico estudos sobre gênero, por meio da perspectiva apresentada pela Judith Butler, e apontamentos conceituais no campo do figurino com leitura sobre publicações do Fausto Viana.
\end{abstract}

Palavras chaves: Gênero; Traje de cena; Criação; Processo.

\section{Introdução}

O Laboratório e criação sobre traje de cena (LABCT) têm como proposta desenvolver estudos práticos e teóricos sobre o traje de cena englobando nele o estudo de gênero. A construção de um figurino agênero, é o grande desafio do grupo de pesquisa; pois envolve questões sociais já construídas ao longo do tempo relacionadas à ideia de corpo, gênero e sexualidades. "A memória cultural é, entre outras coisas, um ato de imaginação e de interconexão. [...] A memória é incorporada e sensual [...], ela liga o profundamente privado com práticas sociais, até mesmo oficiais; às vezes a memória é difícil de evocar, mas é altamente eficiente [...]” (TAYLOR, D. 1950). Tratar essas questões que já se encontram tão convencionadas no ambiente social de gênero de maneira "avessa” nos faz ir contra a "nossa construção social”.

Perceber a existência da ordem de gênero é fácil; compreendê-la, não. Há conflitos sobre gênero, [...] e alguns problemas relativos ao gênero são genuinamente difíceis de serem resolvidos. Ainda assim temos uma grande riqueza de conhecimento sobre gênero[...], e um repositório de experiências práticas do que constitui uma reforma no gênero. (Moschkovich, M., Connell, R.p.36)

Por meio de estudo de Judith Butler (2013) podemos confrontar a ordem hegemônica e sistêmica que encontramos ao problematizarmos as instancias de corpo, gênero e prática sexual. Segundo a autora, toda essa ordem que correlaciona estás 
instancia são construções oriundas do social e padronizada por vários discursos como naturais diante da ideia de homem e de mulher.

Acompanhando outros estudos e afirmando que a instância gênero é uma construção a autor nos abre um caminho para questionarmos outras parcelas que estão no social que demarcam o gênero como binário e dicotômico: homem e mulher, ou seja, a partir da fragilização do conceito podemos perceber que a vestimenta entendia enquanto código é uma instância que ajuda na compartimentação binária do individuo. Fragilizar essa ideia é buscar vias que não generifique a vestimenta, tornando elas roupa sem ter o direcionamento de marcar gênero.

Desta forma, a ideia de desgenerificar a vestimenta adentra de forma sistemática o trabalho de criação do figurinista entendendo que questões do social adentram o campo criativo das artes, seja ela dança, teatro e musica.

O traje de cena é uma indumentária utilizada nas artes cênicas, o figurino é parte integrante da encenação, teatro, dança, circo, performance; o processo de construção do traje de cena abrange as seguintes etapas: analise do texto dramatúrgico, estudo de referências, criação de croquis, busca dos matérias, confecção dos traje de cena, ensaio com o figurino, prova final (com os retoques) e por fim o uso do figurino na cena propriamente dita.

Segundo o Fausto Viana (2015), a ideia de figurino tem por obrigação, no estado convencional de criação, demarcar alguns signos que levem ao publico a reconhecer, sobretudo, a classe social da personagem, o clima geográfico onde se passa a cena, e o gênero da personagem. Desta forma, como fragilizarmos a instância de gênero, sem comprometer a função simbólica do traje de cena na ação cênica?

\section{Primeiros cortes - Processo criativo}

O processo de criação do traje de cena, foi uma tarefa árdua, a priore trabalhamos juntos com os alunos da disciplina de encenação do curso de Licenciatura em Teatro da Universidade Federal do Maranhão, lecionada pela professora Dr ${ }^{\mathrm{a}}$ Michele Cabral. A leitura do projeto de encenação do aluno Thomaz Paiva, “Gritos Calados”, foi essencial para a construção do figurino, pois diante do projeto de cena puder construir as minhas redes de negociação com a encenação que no caso era o aluno Thomaz. Neste primeiro momento já puder exercitar uma das primeiras instâncias de negociação do figurinista que é com as idéias do diretor da cena ou espetáculo. 
Diante de varias pesquisas com base nas informações do texto, com base na escolha estética do diretor para a cena, e com a liberdade que o mesmo projeto em mim para as articulações em gênero por meio do figurino foram inúmeras as tentativas de compreender um único processo direcional para estas questões.

A primeira tentativa foi contra todos os debates trazido em sala de aula, não condizia com a proposta do grupo de pesquisa, o figurino ressaltava a silhueta e o busto; o tecido escolhido (lamê) no corpo masculino não deu o resultado desejado. “A silhueta pode ser definida pelo corte, pela escolha e modelagem da matéria-prima ou por elementos que acentuam ou distorcem a figura humana natural [...] (ANGUA, Emily. p.34)”. Já a segunda tentativa e definitiva; quis fazer, não tirando características da primeira; utilizei duas peças a blusa representava a dupla personalidade da personagem, um lado era manga comprida com ombreira, nela tinha pequenos origamis em formato de prisma que simulava os conflitos internos da personagem e uma calça, fiz uma releitura da roupa social “masculina”.

\section{Croqui da primeira tentativa}

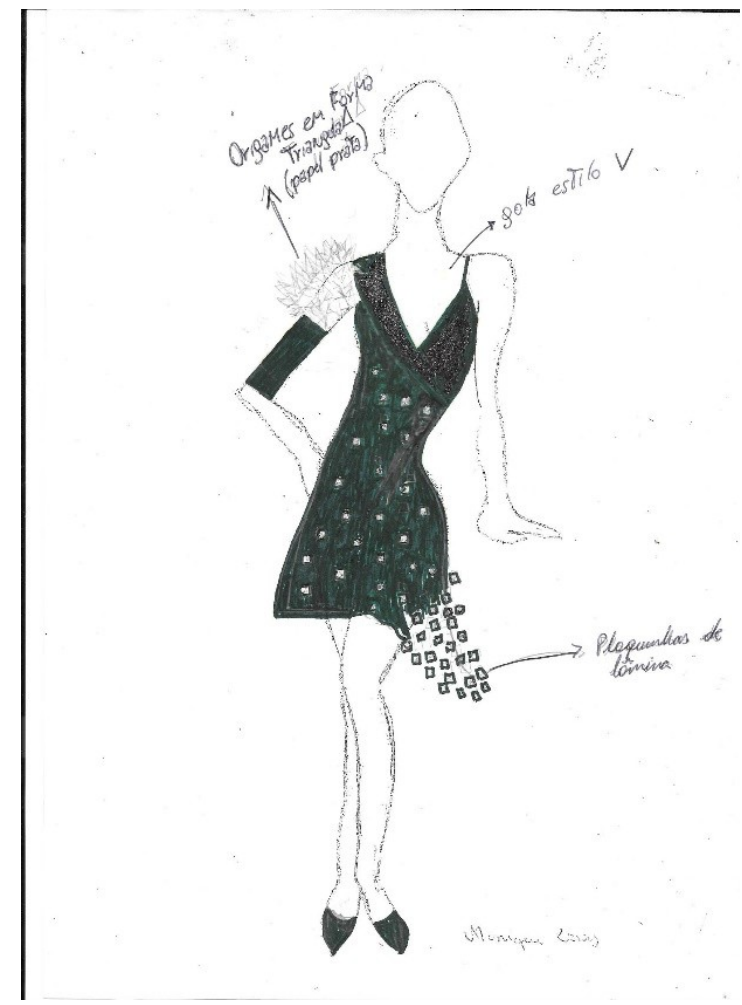

Fonte: Registro do diário do (a) figurinista 
Desta forma, percebi que a via de criação que estava levando o meu processo criativo foi por meio da pesperctiva da modelagem; aspecto estudado e refletido nos encontros do LABTC, pois busquei por meio da minha criação não demarcar a cintura, nem busto, marquei o quadril ficando uma espécie de esquine folgada; utilizei filó para a ombreira, o tecido lamê para toda a composição do figurino, pois, ele condizia com a proposta do projeto de encenação. Utilizei pequenos espelhos em toda a indumentária já que a proposta do projeto de encenação era fazer com que o público se visse refletido tanto na fala e ações da personagem, como no figurino que ela estava usando. Era como se o figurino refletisse a reação do público para com a cena.

Croqui da segunda tentativa

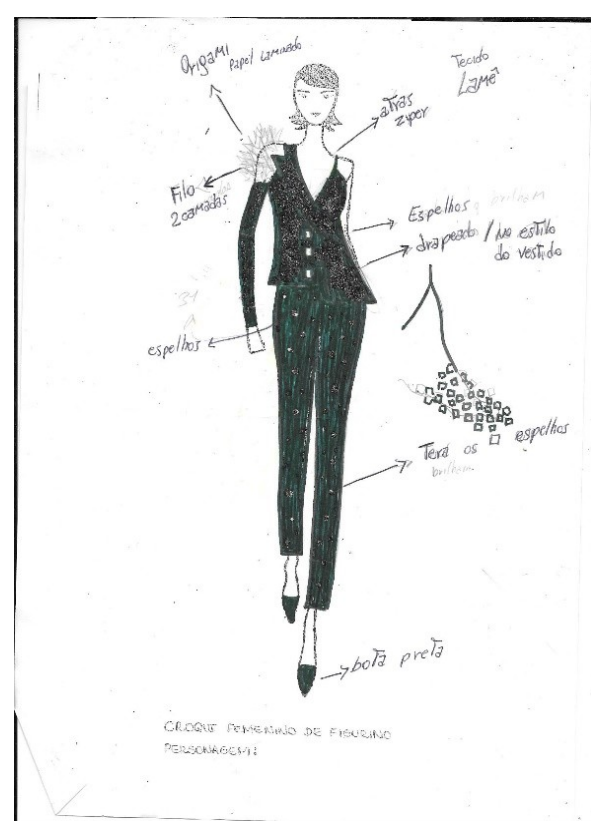

Fonte: Registro do diário do (a) figurinista

Para a efetivação do figurino, o maior desafio foi encontrar uma costureira que aceitasse o trabalho a ordem de uma criação especifica para teatro, (o período de final de ano é inviável uma costureira pegar um trabalho para realizar em apenas 3 dias) foi uma busca incessante, percebi que 0 mercado da costura em São Luís- Maranhão, anseia por profissionais qualificados que costurem tecidos, e para uso exclusivo para teatro. A grande maioria trabalha com malha. Como o tempo determinado para a confecção do 
figurino foi curto, a solução constituiu na minha imersão na elaboração do figurino, me debrucei junto com a costureira e trabalhamos juntas, sábado e domingo, para que na terça-feira o traje de cena estivesse pronto. Nos retoques finais percebi que o material utilizado não foi uma das melhores escolhas, utilizei-me de um corpo masculino para dá os últimos ajustes, pois a atriz não estava disponível; percebi a grande problemática: braços grossos, costas largas, peitoral sinuoso. Como construir um figurino sem denominar gênero, trazendo a modelagem como referência, com todo esse contexto social já impregnado?

Pensar no uso do tecido é fundamental em um processo oriundo da modelagem. Ser figurinista é entender a vestimenta seus aspectos culturais e sociais e sua inclusão no mundo do teatro.
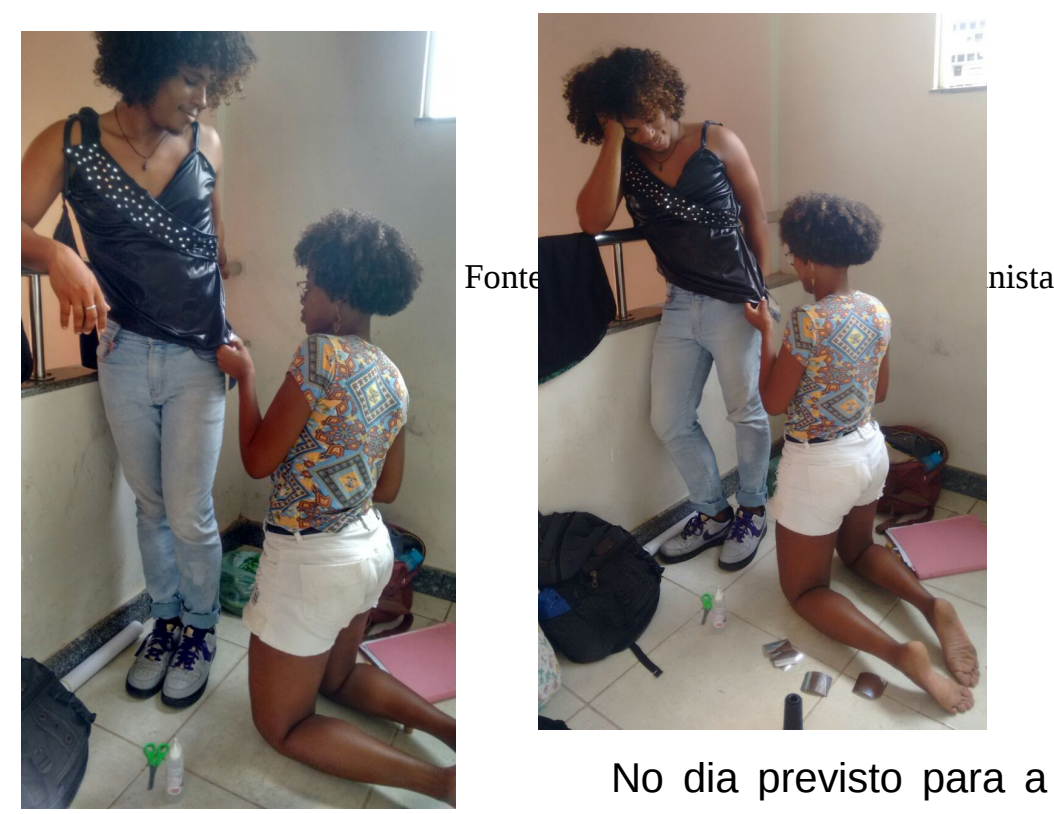

No dia previsto para a

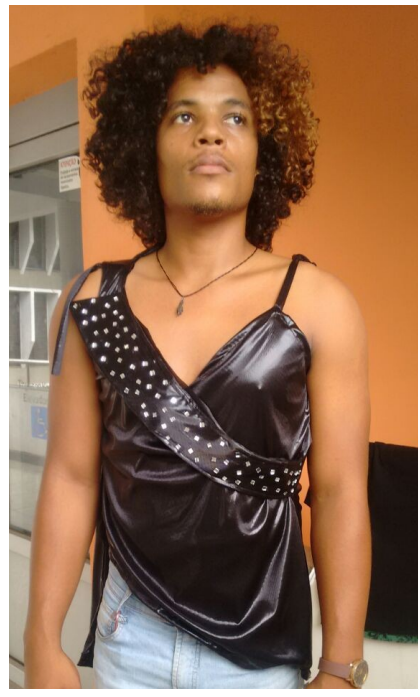

encenação, o figurino casou perfeitamente com a iluminação e cenário, trazendo o desconforto previsto para a platéia. Segundo relatos de algumas pessoas que estavam na platéia o efeito do traje na cena se deu já que "a luz batendo na roupa (espelhos) da personagem me trouxe um incomodo, minha vista desviava para outra direção, refletida na parede pareciam vagalumes" Leticia Sousa aluna de artes Visuais.

A pretensão deste trabalho foi de alcançar de forma criativa, a proposta de um figurino agênero, talvez não com tanto êxito mais contribuiu para a 
formação de um novo pensar sobretraje de cena; compreendendo as dificuldades mais com a intenção de ultrapassar barreiras com inovação.

Bibliografia:

BUTLER, Judith. Problemas de gênero: feminismo e subversão de identidade. Rio de Janeiro. Civilização brasileira, 2003.

VIANA, Fausto; PEREIRA, Dalmir Rogério. Figurino e cenografia para iniciantes. São Paulo. Estação das letras.

ANGUA, Emily. Dicionário da moda. 2015.São Paulo. Publifolha. 2015.

CONNEL. Raewyn;; PEARSE. Rebecca. Gênero uma perspectiva globalcompreendendo o genrero- da esfera pessoal a politica- no mundo contemporaneo.2016. 

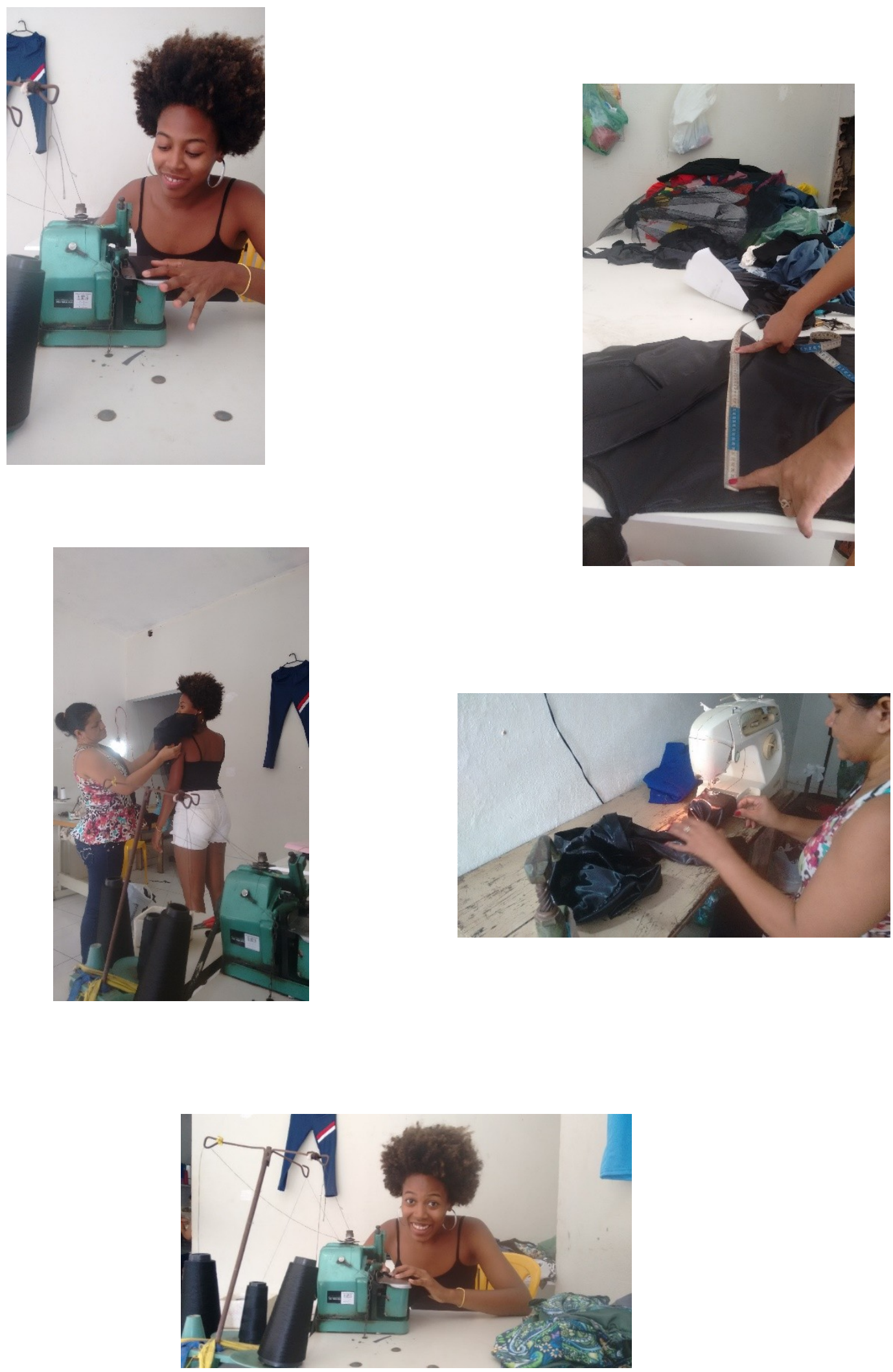

Galoá \{ Este trabalho foi publicado utilizando o Galoá proceedings 